\title{
Tailoring pulp cellulose with electron beam irradiation: Effects of
} lignin and hemicellulose.

Oliver P. Sarosi ${ }^{\dagger}$, Robert H. Bischof ${ }^{\ddagger}$, Antje Potthast*I

${ }^{\dagger}$ Kompetenzzentrum Holz GmbH, Werkstraße 2, A-4860 Lenzing

${ }^{\ddagger}$ Lenzing AG, Werkstraße 2, A-4860 Lenzing

IInstitute of Chemistry of Renewable Resources, Department of Chemistry, University of Natural Resources and Life Sciences, Konrad-Lorenz-Straße 24, A-3430 Tulln

*Phone: +43 1 47654-77412, 77471, e-Mail: antje.potthast@boku.ac.at

Number of pages: 4

Number of figures: 5

Number of tables: 4 


\section{Molecular weight reduction kinetics using EBI}

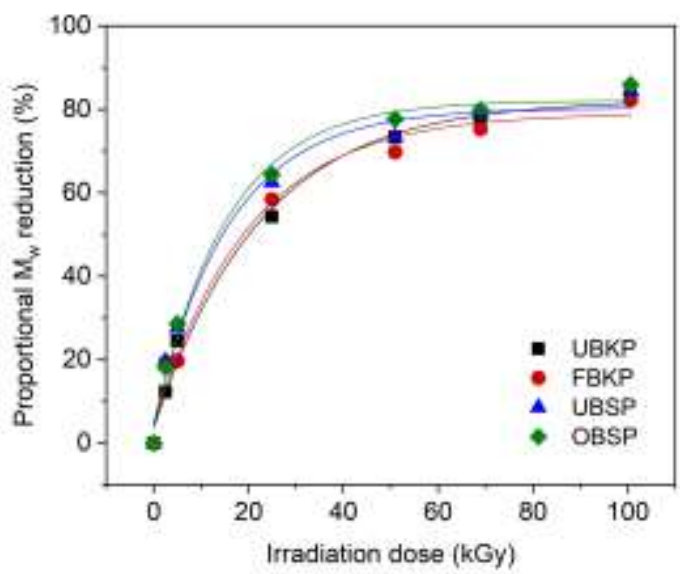

Figure S1: Molecular weight reduction of pulps by electron beam irradiation in proportion to the untreated pulp.

Table S1: Molecular weight data of irradiated pulps.

\begin{tabular}{|c|c|c|c|c|}
\hline $\begin{array}{c}\text { Irradiation dose } \\
(\mathrm{kGy})\end{array}$ & $\begin{array}{c}\mathrm{UBKP} \mathrm{M}_{\mathrm{w}} \\
\left(\mathrm{kg} \mathrm{mol}^{-1}\right)\end{array}$ & $\begin{array}{c}\mathrm{FBKP} \mathrm{M}_{\mathrm{w}} \\
\left(\mathrm{kg} \mathrm{mol}^{-1}\right)\end{array}$ & $\begin{array}{c}\text { UBSP M }_{\mathrm{w}} \\
\left(\mathrm{kg} \mathrm{mol}^{-1}\right)\end{array}$ & $\begin{array}{c}\text { OBSP M }_{\mathrm{w}} \\
\left(\mathrm{kg} \mathrm{mol}^{-1}\right)\end{array}$ \\
\hline 0 & 424 & 380 & 353 & 329 \\
\hline 2.5 & 372 & 306 & 284 & 270 \\
\hline 5.0 & 320 & 305 & 256 & 235 \\
\hline 25 & 194 & 158 & 132 & 117 \\
\hline 50 & 113 & 115 & 94 & 73 \\
\hline 75 & 95 & 94 & 74 & 66 \\
\hline 100 & 71 & 67 & 55 & 46 \\
\hline
\end{tabular}

Table S2 contains the constants for the Boltzmann-fits describing the weight average molecular mass $\left(M_{w}\right)$ of every respective pulp as a function of the applied electron beam irradiation dose. The general formula of the Boltzmann fits is given in Eq. 1.

$$
y=A 2+\frac{(A 1-A 2)}{\left(1+e^{\frac{x-x_{0}}{d x}}\right)}
$$

Where

$y$ is the weight average molecular weight $\left(M_{w}\right)$

$\mathrm{x}$ is the electron dose in kGy

The necessary rearrangement to calculate the required electron dose for a desired $M_{w}$ reduction is given in Eq. 2. 


$$
x=x_{0}+d x * \ln \left(\frac{A 1-A 2}{y-A 2}-1\right)
$$

Table S2: Constants describing the Boltzmann-fit of $M_{w}$ as a function of electron beam irradiation dose for four pulps.

\begin{tabular}{|l|l|l|l|l|l|}
\hline Pulp & $\mathrm{A} 1$ & $\mathrm{~A} 2$ & $\mathrm{x}_{0}$ & $\mathrm{dx}$ & $\mathrm{R}^{2}$ \\
\hline UBKP & $407 * 10^{3}$ & 75.2 & -160 & 22.5 & $99.3 \%$ \\
\hline FBKP & $369 * 10^{3}$ & 79.3 & -143 & 20.0 & $98.6 \%$ \\
\hline UBSP & $542 * 10^{3}$ & 69.5 & -121 & 15.9 & $98.8 \%$ \\
\hline OBSP & $460 * 10^{3}$ & 58.8 & -114 & 15.2 & $99.2 \%$ \\
\hline
\end{tabular}

\section{Molecular weight distribution}
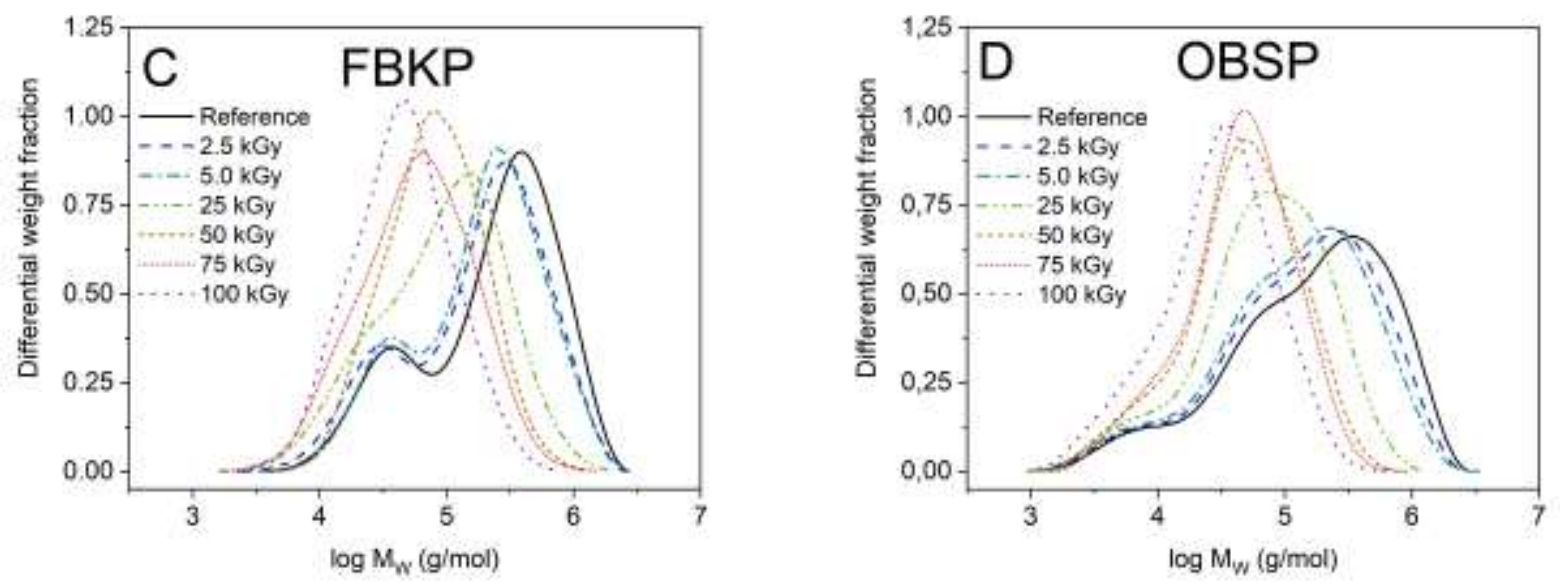

Figure S2: Molecular weight distribution of (C) fully bleached Kraft pulp, and (D) oxygen-bleached sulfite pulp after electron beam irradiation at varying doses

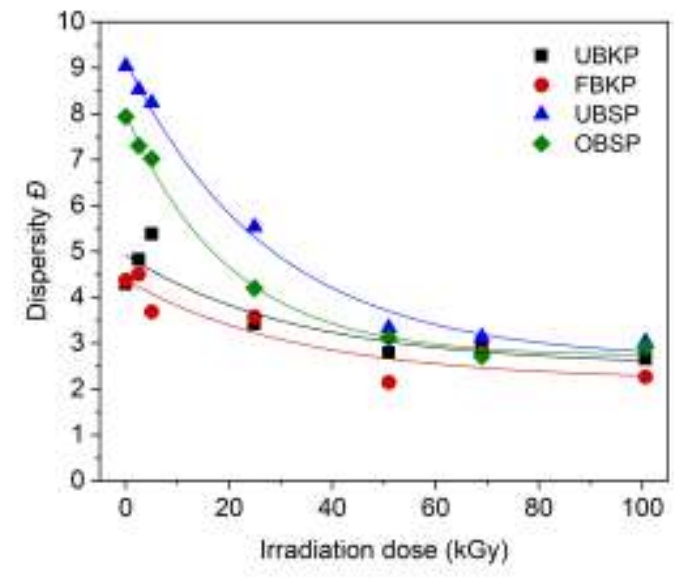

Figure S3: Dispersity $Ð$ of irradiated pulps. 


\section{Cellulose chain scission}

Table S3: Linear fit functions describing the number of chain scissions of pulps by electron beam irradiation with varying dose.

\begin{tabular}{|l|l|l|l|}
\hline Pulp & Slope & Intercept & $R^{2}$ \\
\hline UBKP & 0.050 & 0.04 & $99.8 \%$ \\
\hline FBKP & 0.045 & 0.08 & $99.6 \%$ \\
\hline UBSP & 0.053 & 0.13 & $99.7 \%$ \\
\hline OBSP & 0.060 & 0.13 & $99.3 \%$ \\
\hline
\end{tabular}

\section{Carbonyl groups}

Table S4: Linear fit functions describing the number of carbonyl groups of pulps irradiated at varying doses, measured by the CCOA method.

\begin{tabular}{|l|l|l|l|}
\hline Pulp & Slope & Intercept & $\mathrm{R}^{2}$ \\
\hline UBKP & 0.556 & 1.51 & $96.4 \%$ \\
\hline FBKP & 0.590 & 14.6 & $99.2 \%$ \\
\hline UBSP & 0.585 & 30.3 & $99.9 \%$ \\
\hline OBSP & 0.633 & 17.1 & $99.8 \%$ \\
\hline
\end{tabular}

\section{Fluorescence quenching investigation}

Fluorescence quenching of the CCOA signal by lignin was investigated to eliminate false positives. Comparing the pulps with the highest irradiation levels, the sulfite pulps showed no signs of quenching in the low molecular region, where lignin is attached to hemicelluloses by lignin carbohydrate complexes (Figure 1). The fully bleached kraft pulp exhibits a slightly higher degree of substitution (DS $\mathrm{CO}_{\mathrm{C}}$ ) and fluorescence signal in the low-molecular region. This observation can be ascribed to the higher carbonyl group content in the respective native material rather than fluorescence quenching. 

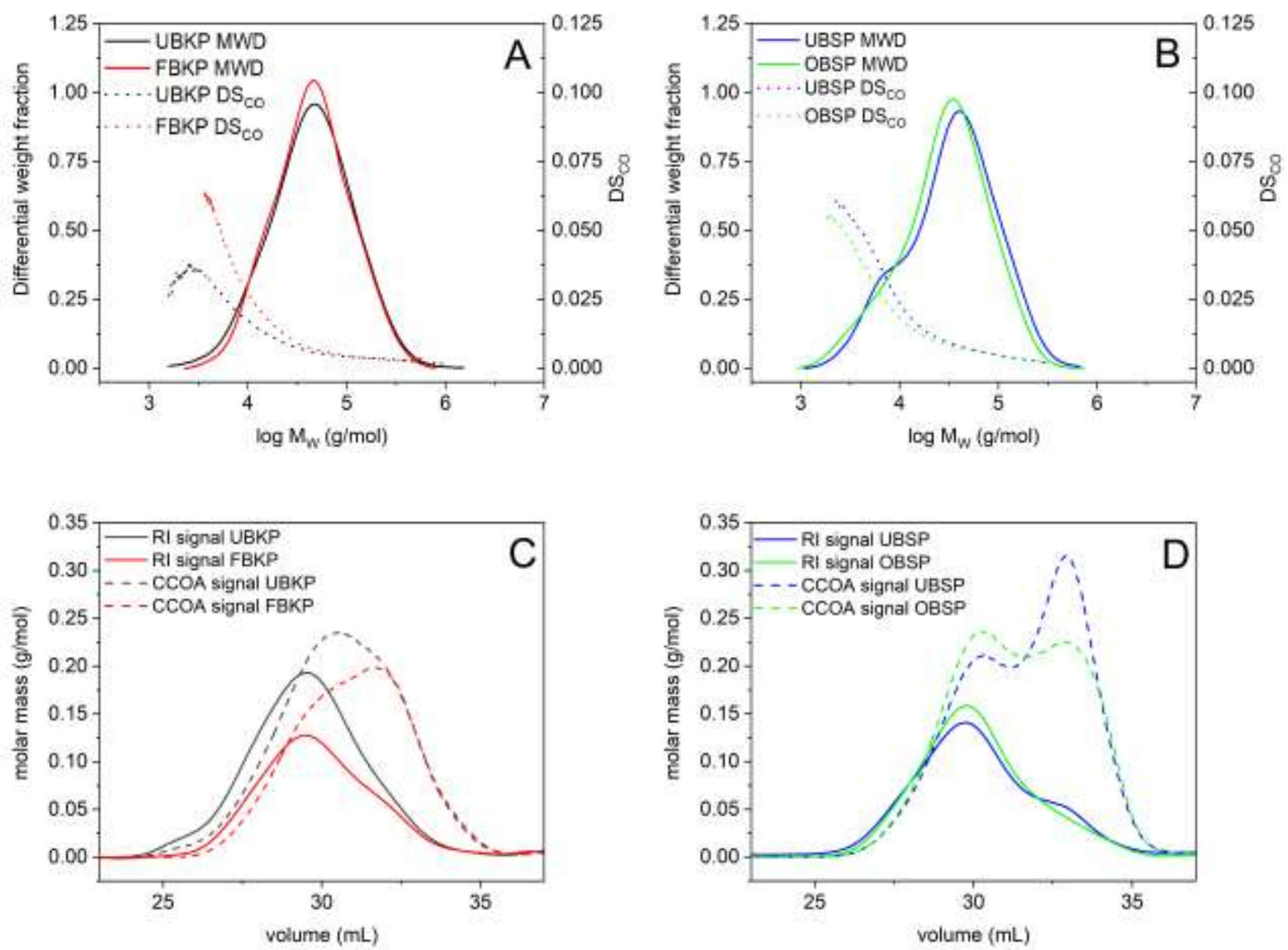

Figure S4: $(A, B)$ Molecular weight distribution with the degree of substitution of carbonyl groups from fluorescence coupled GPC and $(C, D)$ the corresponding raw measurement diagrams of Kraft and sulfite pulps after irradiation at $100 \mathrm{kGy}$.

\section{Differential carbonyl group distribution}
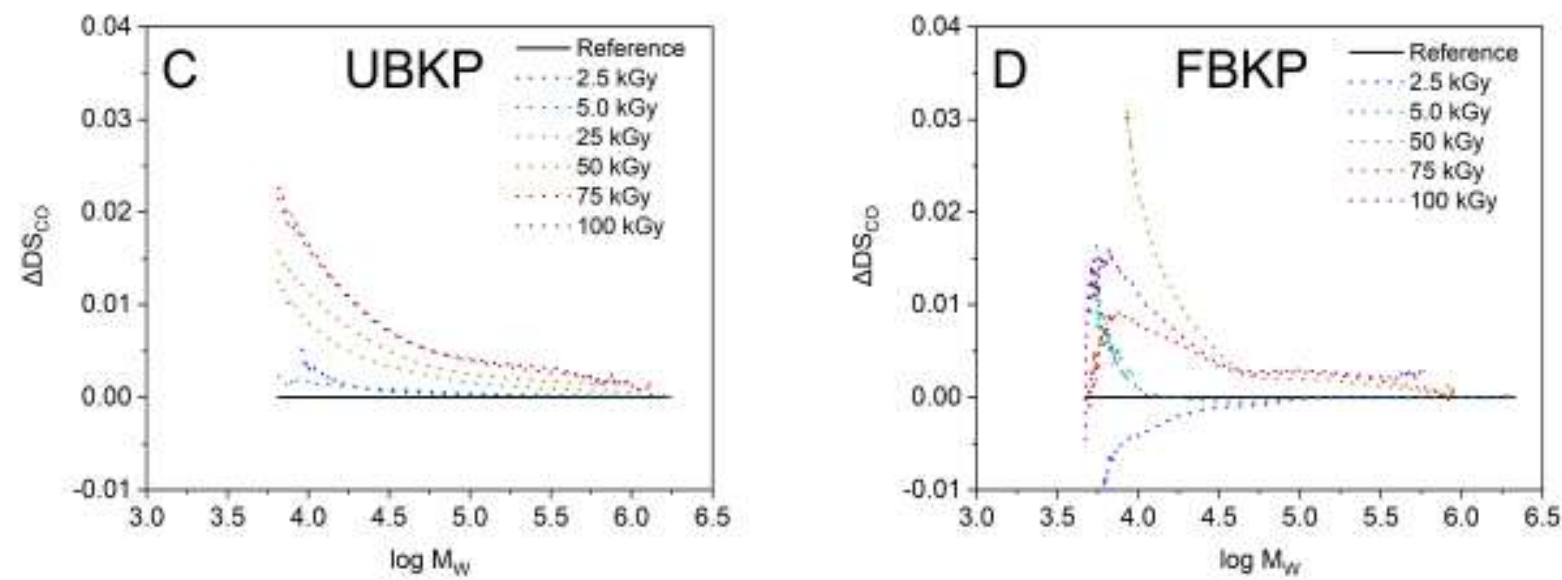

Figure S5: Differential degree of substitution of carbonyl groups in (C) unbleached Kraft pulp, (D) fully bleached kraft pulp after electron beam irradiation. 